collapsed regions driving bits of fluid around. Such networks could be used in microfluidics devices such as labs on chips.

Recent efforts are focusing on enabling this general process on the micrometer and smaller scales. This presents a huge challenge, requiring the synthesis of singlecrystal films of martensitic and closely related materials that have complex crystal structures and nonstoichiometric compositions. Recently, researchers armed with a
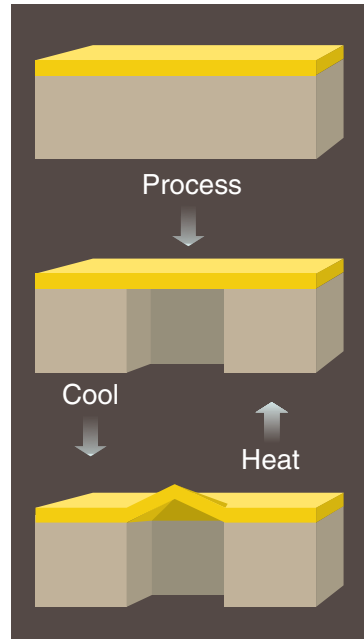
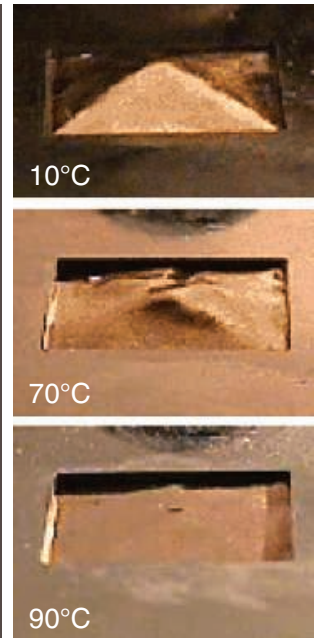

How materials may act as machines. (Left) Schematic cross section of a film, released on a square, showing a tent-like deformation produced by phase transformation. (Right) Realization of such a deformation in a CuAINi foil, released on a $1 \mathrm{~cm}$ by $1 \mathrm{~cm}$ region, produced by heating and cooling the film. variety of methods have grown such films of perovskite oxides (13-15) and alloys related to $\mathrm{Ni}_{2} \mathrm{MnGa}$ (16). (The former are ferroelectrics, whereas the latter alloys are both martensitic and ferromagnetic.) These materials have another interesting feature for material-as-machine: In addition to the distortion, the individual domains are also electrically or magnetically polarized. Thus, instead of causing the shape change by heating or cooling, one can do it by applying a magnetic or electric field, opening up a host of possibilities including remote actuation. Early results are encouraging. For example, Nagarajan et al. (17) have shown that the domains can be altered by patterning the film and that this method can be exploited to build small-scale actuators.

Given their huge work output per volume and their small scale, materials-as-machine may be best suited for biomedical applications. At these microscopic scales, the forces needed to overcome the enormous constraining effects of both surface tension and viscosity are daunting for microelectromechanical systems. The ideal machine for such applications might in fact be made of proteins.

It turns out that nature already uses such a material-as-machine. Bacteriophage $\mathrm{T}-4$ virus has a tail sheath made of a single-domain protein that undergoes a martensitic transformation (18). During invasion of the host, virus-host interactions trigger the transformation in the sheath, driving a hollow protein needle through the cell wall of the bacterium through which its DNA is passed. It would be fascinating to create a humanmade analog of the virus's tail sheath. Recent progress in the theory, synthesis, and fabrication of martensitic materials suggests that this idea is ready to explore.

\section{References}

1. K. Bhattacharya, Microstructure of Martensite: Why It Forms and How It Gives Rise to the Shape-Memory Effect (Oxford Univ. Press, Oxford, 2003).

2. K. Bhattacharya, S. Conti, G. Zanzotto, J. Zimmer, Nature 428, 55 (2004).

3. X. Huang, G. Ackland, K. Rabe, Nature Mater. 2, 307 (2003).

4. G. B. Olson, W. S. Owen, Martensite (ASM International, Materials Park, OH, 1992).

5. P. F. Van Kessel, L. J. Hornbeck, R. E. Meier, M. R. Douglas, Proc. IEEE 86, 1687 (1998).

6. P. Krulevitch et al., J. MEMS 5, 271 (1996).

7. A. Ishida, A. Takei, S. Miyazaki, Thin Solid Films 228, 210 (1993)

8. D. L. Polla, L. F. Francis, Annu. Rev. Mater. Sci. 28, 536 (1998).

9. R. H. Wolf, A. H. Heuer, J. MEMS 4, 206 (1995)

10. A. Braides, Gamma-Convergence for Beginners (Oxford Univ. Press, Oxford, 2002).

11. K. Bhattacharya, R. D. James, J. Mech. Phys. Solids 47, 531 (1999)

12. J. Cui, R. D. James, in preparation.

13. V. Nagarajan, C. S. Ganpule, R. Ramesh, Top. Appl. Phys. 93, 47 (2004).

14. S. W. Boland, S. C. Pillai, W. D. Yang, S. M. Haile, J. Mater. Res. 19, 1492 (2004).

15. Y. B. Park, J. L. Ruglovsky, H. A. Atwater, Appl. Phys. Lett. 85, 455 (2004)

16. J.W. Dong et al., J. Appl. Phys. 91, 2593 (2004).

17. V. Nagarajan et al., Nature Mater. 2, 43 (2003).

18. G. B. Olson, H. Hartman, J. de Phys. 43, C4-855 (1982).

$10.1126 /$ science. 1100892

\title{
Policing Insect Societies
}

\section{Francis L. W. Ratnieks and Tom Wenseleers}

$\mathbf{T}$ he London Bobby is a reassuring symbol of civic order (1). But this symbol is also a reminder that human societies have conflicts. Insect societies, too, experience internal conflicts (2), and research increasingly shows that policing is important to resolve these. Within both human and insect societies, conflicts arise because the interests of individuals differ. In insect societies, conflict revolves around reproduction. Reproducing individuals gain by being more closely related to the young males and queens reared in their colony. By reproducing, society members also exploit the colony and this can be cost-

The authors are in the Laboratory of Apiculture \& Social Insects, Department of Animal \& Plant Sciences, University of Sheffield, Sheffield S10 2TN, UK, and the Institute of Advanced Study, Berlin 14193, Germany. ly. First, uncontrolled reproduction upsets the division of labor between queen and workers and results in a less efficient colony. Second, the offspring reared are often genetically less related and so are less valuable to other society members.

To prevent exploitation, social insects have evolved several methods of policing. The best known is "worker policing," whereby workers kill eggs laid by other workers. This phenomenon was first discovered in the honeybee 15 years ago (3). Since then, it has been discovered in more than 15 species of bee, wasp, and ant. This past year alone, five more insect speciestwo species of British wasp (4) and three ant species from Florida (5), Brazil (6), and Finland (7) - have been added to the list.

In addition to reducing reproduction by workers, policing also acts to regulate the development of females into distinct queen and worker castes, and to prevent excess females from developing into queens (8). When different species are compared, one important overall conclusion emerges: More effective policing results in fewer individuals acting selfishly. There are other striking parallels to human society: Insect policing relies on both detection and prevention, and individuals sometimes attempt to evade policing (see the figure).

In the life of any female bee, wasp, or ant, there are two points at which she may try to reproduce. The first is when, as a larva, she starts developing into either a queen or a worker. In most species, queens are morphologically specialized for egg laying and are often incapable of working. The second is when, as an adult worker, she decides whether to activate her ovaries to lay eggs. In most species, workers cannot mate yet retain ovaries. Therefore, they can lay unfertilized eggs, which develop into males if reared.

Young female larvae of bees, wasps, and ants are usually totipotent, that is, they have the potential to develop into either a queen or a worker. A larva is often better off developing into a queen, yet policing 
ensures that most are prevented from doing so. Because queens are generally larger than workers and need more food, adult workers can control whether a larva will develop into a queen by controlling her food supply. Consider the honeybee (8). A colony reproduces by swarming, dividing into several colonies each headed by the mother queen or a newly reared daughter queen. Prior to swarming, a few queens and thousands of workers are reared. Thus, although a few larvae are reared into queens, with a good chance of heading a colony, thousands of their less fortunate sisters are reared into workers. The fitness advantage of developing into a queen is large. If she ends up heading a colony, the workers will rear her offspring, to which she is related by 0.5 . But larvae reared into workers would rear the offspring of a sister queen, to which they are related by only 0.15 .

Theory (8) shows that about half the honeybee larvae would become queens if they had the power to choose their own caste fate, even though only a few will ever head a colony. Basically, the lottery to reproduce is so attractive that many more enter than could possibly win the prize of heading a new colony. However, the more that enter the lottery, the worse it is for the colony as a whole. This is because queens cannot work. By policing larval development, workers prevent excess queens from being reared and the society operates more efficiently. In essence, what happens is that the workers carefully select and rear a few entrants to the lottery. Entry by all is prevented because there are only a few special large cells in the brood comb in which queens can be raised.

The rearing of queens and workers is so well regulated that only recently has the realization struck that female larvae may try to develop into queens when this is not in their colony's best interest. Stingless bees are the exception that proves the rule. Like honeybees, stingless bees reproduce by swarming and have queens that cannot work. Unlike honeybees, however, they often produce excess queens. Because these queens can serve no useful purpose in the colony, these unfortunate creatures are beheaded or torn apart by the workers soon after they emerge from their cells in the brood comb (9). The greatest profligacy occurs in the tropical American genus Melipona, with up to $20 \%$ of the female larvae developing into queens

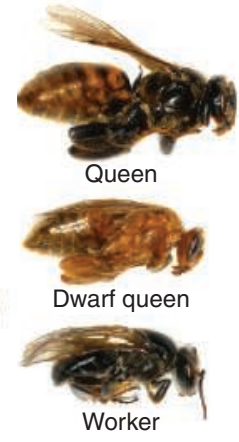

PER S PECTIVES

by reducing their food supply is not a fully effective preventive measure in these species. A recent study of one stingless bee species from Brazil, Schwarziana quadripunctata, does reveal, however, that dwarf queens are less successful than normal-sized queens, partly because many of the dwarf queens are killed by the workers (11). As a result, fewer excess Schwarziana queens (about $0.5 \%$ of all females) are reared than in the Melipona species.

The regulation of queen rearing shows that policing entails prevention, normally making it impossible for larvae to act selfishly by choosing to develop into a queen rather than a worker (see the figure). The second selfish reproductive strategy, egg laying by workers, demonstrates that policing in insect societies also entails detection: Workers detect and kill workerlaid eggs, thus making it difficult for a selfish worker to profit from her action. A worker bee, wasp, or ant has a strong incentive to lay eggs because she is more related to sons $(0.5)$ than to brothers (queen's sons, 0.25 ) or nephews (other workers' sons, 0.125 to 0.375 ). But in many species workers, and sometimes even the queen, kill

compared with only about $0.01 \%$ in the honeybee (10). This excess exists because preventive policing is impossible. Queen and worker Melipona have the same body mass (but not shape) and are reared in identical sealed cells, each with its own food supply (see the figure). In contrast, honeybee larvae are reared in open cells and fed progressively, and the cells for queen larvae are bigger than those for worker larvae. As a result, a female Melipona larva has enough food to develop into either a queen or a worker and does so while isolated from any intervention by the adult workers. The honeybee, by contrast, has an elegant system of policing, which ensures that only larvae in special queen-size comb cells develop into queens.

Other stingless bees are normally able to prevent excess queen rearing because queens are larger and are reared in special large cells provisioned with extra food. However, larvae reared in smaller cells, which usually would be used to rear workers, sometimes evade their intended fate by developing into dwarf queens. Such dwarf queens are the same size as workers but can still successfully head a colony. Thus, preventing larvae from developing into queens worker-laid eggs. The effectiveness of this
egg policing varies. In the common wasp Vespula vulgaris (which nests below ground or in lofts) and the honeybee, almost all (about 98\%) of the worker-laid eggs are killed, whereas in Dolichovespula wasps (which build football-shaped nests in the open) only 80 to $90 \%$ are killed. When policing is more effective, the benefit of laying eggs diminishes so that fewer workers lay eggs. In keeping with this prediction, the proportions of egg-laying workers are much lower in honeybee $(0.001$ to $0.01 \%)$ and common wasp colonies (1\%) than in Dolichovespula (10\%) (12).

Egg-laying workers sometimes can evade policing. Eggs laid by anarchistic and parasitic Cape honeybee workers are less closely policed than normal worker-laid eggs $(13,14)$, probably because they chemically mimic eggs laid by the queen. In ants, workers have another potential means for evading policing. Because ants keep their eggs in piles, it was thought that workers could make their eggs smell queenlike by placing them in the pile. A recent study, however, found that mingling with the queens' eggs offers little protection, perhaps because the queen marks her eggs with 
chemicals that are not readily transferred (15).

Both insects and humans police their societies. Are there any common principles? Can humans learn anything from insect policing? The principal lesson seems to be that policing is a common feature of social life and helps to resolve the conflicts caused by the transition from individuals to societies (16). Bees, wasps, and ants each evolved eusociality independently, thus policing must have evolved multiple times. One challenging research question in human policing concerns the effectiveness of different intensities and methods of policing (17). This is important because human policing is costly. One 1988 Australian study estimated the annual cost of one additional full-time (24/7) patrol car at $\mathrm{A} \$ 300,000$ (18). By showing that individuals are less likely to exploit society when policing is more effec- tive, studies of insects indicate that effective policing can induce individuals to act in ways that are better for society. In insect societies, this means that policing consolidates the basic inequality between queens and workers. Policing in human societies has been used by repressive regimes to sustain inequalities, as demonstrated by the negative connotation of the phrase "Police State." But a human society in which policing is used to promote greater equality and justice may not be an unattractive prospect.

\section{References}

1. The Proceedings of the Old Bailey. Policing in London Before the Bobbies. www.oldbaileyonline.org/ history/crime/policing.html.

2. A. F. G. Bourke, N. R. Franks, Social Evolution in Ants (Princeton University, New Jersey, 1995).

3. F. L. W. Ratnieks, P. K. Visscher, Nature 342, 796 (1989).

4. T. Wenseleers et al., Evolution, in press.
5. A. Endler et al., Proc. Natl. Acad. Sci. U.S.A. 101, 2945 (2004).

6. P. D'Ettorre et al., Proc. R. Soc. London. Ser. B 271 , 1427 (2004).

7. H. Helanterä, thesis (University of Helsinki, 2004)

8. T. Wenseleers et al., J. Evol. Biol. 16, 647 (2003).

9. T. Wenseleers et al., Ethology 110, 725 (2004).

10. T. Wenseleers, F. L. W. Ratnieks, Proc. R. Soc. London Ser. B (Suppl.) 271, S310 (2004).

11. T. Wenseleers et al., Proc. R. Soc. London Ser. B (Suppl.), in press.

12. T. Wenseleers et al., J. Evol. Biol. 17, 1035 (2004).

13. B. P. Oldroyd, F. L. W. Ratnieks, Behav. Ecol. Sociobiol. 47, 268 (2000).

14. S. J. Martin et al., Nature 415, 163 (2002).

15. P. D'Ettorre et al., in preparation.

16. J. Maynard Smith, E. Szathmáry, The Major Transitions in Evolution (Freeman, Oxford, 1995).

17. W. Skogan, K. Frydl, Eds., Fairness and Effectiveness in Policing: The Evidence (The National Academies Press, Washington, DC, 2004).

18. P. N. Grabosky, "Efficiency and effectiveness in Australian policing" (report no. 16, Australian Institute of Criminology, Canberra, 1988).

10.1126/science. 1106934

\section{Decoding Calcium Signaling}

\section{Monte M. Winslow and Gerald R. Crabtree}

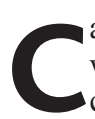
alcium ions $\left(\mathrm{Ca}^{2+}\right)$ may be the most widely used second messenger molecules in biology. Indeed, $\mathrm{Ca}^{2+}$ is essential for early development of organisms, immune responses, and even for remembering what you are about to read. The diverse tasks of $\mathrm{Ca}^{2+}$ raise the question of the molecular origins of specific $\mathrm{Ca}^{2+}$ responses. Two recent papers in Science, by Badou et al. on page 117 of this issue (1) and by Launay et al. (2), identify new players that regulate the movement of $\mathrm{Ca}^{2+}$ into and out of cells, providing a more complete understanding of $\mathrm{Ca}^{2+}$ responses in the immune system.

Activation of the $\mathrm{T}$ cell receptor (TCR) by ligand initiates a rapid influx of $\mathrm{Ca}^{2+}$ into $\mathrm{T}$ cells. This leads to the activation of a phosphatase called calcineurin and the subsequent nuclear import and assembly of NFAT transcription complexes, which switch on and off the expression of genes essential for $\mathrm{T}$ cell development and function (3). Calcineurin is the target of the immunosuppressive drugs cyclosporine A and FK506, the discovery of which ushered in the modern era of organ transplantation. The importance of $\mathrm{Ca}^{2+} / \mathrm{cal}-$ cineurin in immune responses and transplantation therapy has generated great interest in how $\mathrm{Ca}^{2+}$ signals are regulated. Badou and colleagues examined the lethargic mouse (1), which carries a mutation in the $\beta_{4}$ subunit of

M. M. Winslow is in the Immunology Program and G. R. Crabtree is in the Departments of Pathology and Developmental Biology at the Howard Hughes Medical Institute, Stanford University, Stanford, CA 94305, USA. E-mail: crabtree@stanford.edu the L-type voltage-gated $\mathrm{Ca}^{2+}$ channel $\left(\mathrm{Ca}_{\mathrm{V}} 1\right)$. Previous work showed that L-type $\mathrm{Ca}^{2+}$ channels are essential for calcineurin activation and NFAT function in neurons (4). Hence it was possible that these channels might also be important for NFAT-dependent transcription in lymphocytes. Indeed, $\mathrm{CD}^{+} \mathrm{T}$ cells from $\beta_{4}$-mutant mice exhibit defects in $\mathrm{Ca}^{2+}$ entry in response to TCR signaling, are defective in NFATc1 and NFATc2 dephosphorylation, and exhibit severe defects in cytokine production. But what role do these voltage-gated channels play in the activation of nonexcitable cells such as T lymphocytes?

$\mathrm{T}$ cells express many different ion channels in their plasma and endoplasmic reticulum (ER) membranes. These channels coordinately regulate the initial $\mathrm{Ca}^{2+}$ spike and sustained $\mathrm{Ca}^{2+}$ elevation after antigenic stimulation of $\mathrm{T}$ cells. In a resting $\mathrm{T}$ cell, $\mathrm{K}_{\mathrm{V}}$ channels regulate the flow of potassium ions $\left(\mathrm{K}^{+}\right)$out of the cell, and sarco-endoplasmic reticulum $\mathrm{Ca}^{2+}$-ATPases (SERCA) transport $\mathrm{Ca}^{2+}$ into the intracellular stores. The resulting resting potential is about -65 $\mathrm{mV}$. When T cells are stimulated by binding of antigenic peptide associated with major histocompatibility molecules to their TCRs, the lipid second messenger inositol 1,4,5trisphosphate $\left(\mathrm{InsP}_{3}\right)$ is generated and triggers the release of $\mathrm{Ca}^{2+}$ from intracellular stores through the $\mathrm{InsP}_{3}$ receptor. This increase in cytoplasmic $\mathrm{Ca}^{2+}$ concentration $\left(\left[\mathrm{Ca}^{2+}\right]_{\mathrm{i}}\right)$ activates the $\mathrm{Ca}^{2+}$ release-activated $\mathrm{Ca}^{2+}$ (CRAC) channels in the plasma membrane. Once the CRAC channel is activated, the $\mathrm{Ca}^{2+}$ influx is driven by the cell's nega- tive resting potential, and the positively charged $\mathrm{Ca}^{2+}$ ions flow into the cell. This constitutes the initial rise in $\left[\mathrm{Ca}^{2+}\right]_{\mathrm{i}}$ observed during the early stages of $\mathrm{T}$ cell activation (see the figure).

Badou et al. (1) provide the first genetic evidence that L-type channels, and specifically $\beta_{4}$-containing L-type calcium channels, may be involved in the initiation of this calcium response in T cells. These channels are composed of $\alpha_{1}, \gamma$, and $\delta$ transmembrane subunits as well as an extracellular $\alpha_{2}$ and an intracellular $\beta$ subunit (5). L-type $\mathrm{Ca}^{2+}\left(\mathrm{Ca}_{\vee} 1\right)$ channels have distinct biophysical properties that enable them to participate in signal transduction. The $\alpha_{1}$ subunit can associate with any of four distinct cytoplasmic $\beta$ subunits $\left(\beta_{1}\right.$ to $\left.\beta_{4}\right)$, all of which may be expressed in T cells ( 6 ). The $\beta$ subunit influences the trafficking of the poreforming $\alpha_{1}$ subunit and modulates the characteristics of the channel (5).

These investigators suggest that signaling via L-type $\mathrm{Ca}^{2+}$ channels influences the initial $\mathrm{Ca}^{2+}$ influx based partly on the currents induced after TCR stimulation. The interpretation that these currents are from $\mathrm{Ca}_{\mathrm{V}} 1$ channels would be better supported if $\beta_{4}$-mutant $\mathrm{T}$ cells failed to produce the TCR-induced currents, which the authors did not test. The presumed coupling of TCR to $\beta_{4}$ raises the possibility that the $\beta_{4}$ or $\alpha_{1}$ subunits are regulated by phosphorylation, as has been shown in other cell types, and that this modification serves to facilitate the activation of these channels. Determining the phosphorylation status of the endogenous channel components after antigen receptor signaling may contribute to further understanding of this mechanism. Given that between 10 and a few hundred channels of each type are expressed per $T$ cell, this will not be an easy task. The phenotype of $\beta_{4}$-mutant $\mathrm{CD} 4^{+} \mathrm{T}$ cells also in- 